Article

\title{
Proposed Standard Test Protocols and Outcome Measures for Quantitative Comparison of Emissions from Electronic Nicotine Delivery Systems.
}

Edward C. Hensel ${ }^{1 *}$, Nathan C. Eddingsaas ${ }^{2}$, Qutaiba M. Saleh ${ }^{3}$, S. Jayasekera ${ }^{4}$, S. Emma Sarles ${ }^{5}$, A. Gary DiFrancesco ${ }^{6}$, and Risa J. Robinson ${ }^{7}$

1 Professor, Department of Mechanical Engineering, Rochester Institute of Technology, Rochester NY, USA; echeme@rit.edu

2 Associate Professor, School of Chemistry and Materials Science, Rochester Institute of Technology, Rochester NY, USA; ncesch@rit.edu

$3 \mathrm{PhD}$ in Electrical and Computer Engineering Student, Rochester Institute of Technology, Rochester NY, USA; qms7252@rit.edu

$4 \mathrm{PhD}$ in Mechanical and Industrial Engineering Student, Rochester Institute of Technology, Rochester NY, USA; gbj6142@rit.edu

$5 \mathrm{PhD}$ in Biomedical and Chemical Engineering Student, Rochester Institute of Technology, Rochester NY, USA; ses9066@rit.edu

6 Associate Research Scientist, Department of Mechanical Engineering, Rochester Institute of Technology, Rochester NY, USA; agdpci@rit.edu

7 Professor, Department of Mechanical Engineering, Rochester Institute of Technology, Rochester NY, USA; rireme@rit.edu

* Correspondence: echeme@rit.edu;

\begin{abstract}
This study introduces and demonstrates a comprehensive, accurate, unbiased approach to robust quantitative comparison of Electronic Nicotine Delivery Systems (ENDS) appropriate for establishing substantial equivalence (or lack thereof) between tobacco products. The approach is demonstrated across a family of thirteen pen- and pod-style ENDS products. Methods employed consist of formulating a robust emissions surface regression model, quantifying the empirical accuracy of the model as applied to each product, evaluating relationships between product design characteristics and maximum emissions characteristics, and presenting results in formats useful to researchers, regulators, and consumers. Results provide a response surface to characterize emissions (total particulate matter and constituents thereof) from each ENDS appropriate for use in a computer model and for conducting quantitative exposure comparisons between products. Results demonstrate that emissions vary as a function of puff duration, flow rate, E-Liquid composition, and device operating power. Further, results indicate that regulating design characteristics of ENDS devices and consumables may not achieve desired public health outcomes; it is more effective to regulate maximum permissible emissions directly. Three emissions outcome measures (yield per puff, mass concentration and constituent mass ratio) are recommended for adoption as standard quantities for reporting by manufacturers and research laboratories. The approach provides a means of (a) quantifying and comparing maximal emissions from ENDS products spanning their entire operating envelope, (b) comparative evaluation of ENDS devices and consumable design characteristics, and (c) establishing comparative equivalence of maximal emissions from ENDS. A consumer-oriented product emissions dashboard is proposed for comparative evaluation of ENDS exposure potential. Maximum achievable power dissipated in the coil of ENDS is identified as a potentially effective regulatory parameter.
\end{abstract}

Keywords: e-cigarette; regulatory science; substantial equivalence; public health; tobacco product comparison.

\section{Introduction}




\subsection{Context of Prior Work}

As detailed previously [1] [2], no widely accepted puffing topographies or emissions outcome measures have been established for use in ENDS emission studies, although emissions have clearly been demonstrated to be dependent upon usage conditions and product characteristics. A proposed vaping machine standard [3] does not reflect the range of use behavior associated with product use but offers a consistent foundation for comparative emissions studies between ENDS. Relatively few emissions results and product characterizations have been reported in the literature in a format which enable a side-by-side comparison between ENDS, such as would be required to establish statistically significant substantial equivalence.

The variety of emissions outcome measures and underlying operating conditions of the ENDS reported in the literature make it difficult to compare results between laboratories and studies. The recent article by Son et al [1] presented emissions data from four ENDS devices. Of the four devices reported, one overlaps with results to be presented here, the JUUL pod-style ENDS. Son reported the nicotine yield as $0.390 \pm .0305$ [mg/puff] (see their Table 3), combined across four E-Liquids (brand names: Virginia Tobacco, Fruit Melody, Crème Brulee and Cool Mint) with a manufacturer reported nicotine concentration of nominally $59[\mathrm{mg} / \mathrm{mL}]$. Son reported nicotine was collected from the aerosol generated by five puffs of the device and captured on a glass fiber filter pad using puff volumes from 67 to 133 [mL] and puff durations from 4 to 5 [s]. The supplemental data provided in the article contains an excellent summary of emission yield per puff (TPM, CO, formaldehyde, acetaldehyde, acetone, acrolein, propionaldehyde, crotonaldehyde, 2-butanone, methacrolein, n-butyraldehyde, benzaldehyde, valeraldehyde, glyoxal, m-tolualdehyde, hexaldehydes) from four ENDS spanning 5 to 7 flow conditions per device. For comparison purposes, the total mass yield per puff from JUUL reported by Son et al is provided in Table 1. The TPM Yield per puff values in Table 1 provide data points for comparison with results presented herein. Unfortunately, nicotine yield per puff was not reported as a function of flow conditions.

Table 1. Excerpted TPM yield per puff results adapted from Son et al [1], Table S6 and S9, with three repeated trials per condition. For JUUL ENDS filled with Fruit Melody E-Liquid having a manufacturer-reported nominal nicotine concentration of $59[\mathrm{mg} / \mathrm{mL}]$.

\begin{tabular}{ccccc}
$\begin{array}{c}\text { Nominal Puff } \\
\text { Flow Rate }[\mathrm{mL} / \mathrm{s}]\end{array}$ & $\begin{array}{c}\text { Nominal Puff } \\
\text { Duration [s] }\end{array}$ & $\begin{array}{c}\text { Nominal Puff } \\
\text { Volume }[\mathrm{mL}]\end{array}$ & $\begin{array}{c}\text { TPM Yield } \\
{[\mathrm{mg} / \text { puff }]}\end{array}$ & $\begin{array}{c}\text { St Dev } \\
{[\mathrm{mg} / \text { puff] }}\end{array}$ \\
\hline 25 & 2 & 50 & 2.00 & 0.20 \\
25 & 3 & 75 & 2.10 & 0.20 \\
25 & 4 & 100 & 2.80 & 0.20 \\
25 & 5 & 125 & 3.30 & 0.30 \\
33 & 4 & 132 & 2.80 & 0.20
\end{tabular}

\subsection{Study Objectives}

The first objective of this study is to demonstrate accurate, unbiased Emission Models (EM) for quantifying emissions generated from a variety of pen- and pod-style ENDS across their respective operating envelope in terms of three proposed standard emissions outcome measures: TPM yield per puff, $\mathrm{Y}_{\mathrm{TPM}}$, mass concentration, $\mathrm{C}_{\mathrm{TPM}}$, and aerosol constituent mass ratio as exemplified by the nicotine mass ratio, fNic. A corollary to the first objective is to demonstrate how the proposed outcome measures may be used to facilitate re-use of results and data between independent laboratories.

The second objective is to identify maximum response characteristics of the EM which may be used to compare relative emissions between products (presented as an emissions characteristics dashboard).

The third objective is to investigate associations between the maximal EM characteristics and underlying product design characteristics. 
The fourth objective is to propose those product characteristics likely to be effective regulatory parameters to achieve positive outcomes related to public health, reduction in harm potential and clinical guidance.

\section{Materials and Methods}

\subsection{Experimental Materials, Methods and Data Set}

Prior work [2] described the materials and methods used for gathering experimental data previously reported. Briefly, test specimens were procured for testing 13 pen- and pod-style ENDS products from commercial vendors. An emissions screening protocol consisted of two series of machine puffing trials, referred to as the "activation duration" family and "activation flow rate" family of trials. Each trial consisted of nominally 50 homogenous puffs, at the conclusion of which the mass decrease of the ENDS and the mass increase of TPM collected on a Cambridge filter pad was measured gravimetrically. The coil resistance of each product was measured using an unbiased four-lead method $[4,5]$ before and after the emissions trials. The propylene glycol to glycerin ratio (PG:GL) of the un-puffed e-liquid was measured using NMR and the nicotine mass ratio of both the un-puffed e-liquid, $\mathrm{fNic}_{\mathrm{Ni}, \mathrm{ELiq}}$ and aerosol collected on each pad, fNic, was determined using GC-MS. The nicotine mass ratio is defined as the ratio of mass nicotine collected on the pad to the total mass collected, and was reported to be largely independent of both flow rate and duration for the 13 low power ENDS studied. The gathered data was analyzed, and the operating envelope of each ENDS device was characterized in terms of four parameters: the minimum aerosolization duration, MinAD, maximum aerosolization duration, MaxAD, minimum aerosolization flow rate, MinAF, and maximum aerosolization flow rate, MaxAF. All underlying data and computed results were published previously as supplemental data [2]. The current work focuses on developing a convenient mathematical representation of emissions across a variety of pen- and pod-style ENDS appropriate for use in conjunction with the previously described [6] and validated [7] behavior-based yield model. Each product configuration tested was referred to with a unique identifier in the form of ECxx-yy, where $x x$ referred to a particular PCU configuration (e.g., a specific coil chosen for the emissions test series, along with the manufacturer name and model number) and yy referred to consumable (i.e., E-Liquid PG:GL ratio, nicotine concentration, flavor, manufacturer and brand name). The product design characteristics of all products tested are summarized in Table 2 .

Table 2. Product design characteristics describing the 13 ENDS PCUS and corresponding consumable used for this investigation. Adapted from [2]

\begin{tabular}{|c|c|c|c|c|c|c|c|c|c|c|}
\hline $\begin{array}{l}\text { Product } \\
\text { ID } \\
\text { Code }\end{array}$ & $\begin{array}{l}\text { Device } \\
\text { Manufacturer }\end{array}$ & $\begin{array}{l}\text { Device } \\
\text { Model }\end{array}$ & $\begin{array}{l}\text { Consumable } \\
\text { Manufacturer }\end{array}$ & $\begin{array}{l}\text { Consumable } \\
\text { Labeled } \\
\text { Flavor }\end{array}$ & $\begin{array}{l}\text { Unpuffed } \\
\text { E-Liquid } \\
f_{\text {Nic }}\end{array}$ & $\begin{array}{l}\text { PG } \\
\text { Fraction } \\
{[-]}\end{array}$ & $\begin{array}{l}\text { Mean } \\
R_{\text {Coil }} \\
{[\Omega]}\end{array}$ & $\begin{array}{l}\operatorname{Max}(1) \\
P_{\text {Nom }} \\
{[\mathrm{W}]}\end{array}$ & $\begin{array}{l}\mathrm{MaxAF} \\
{[\mathrm{mL} / \mathrm{s}]}\end{array}$ & $\begin{array}{l}\operatorname{MaxAD} \\
{[s]}\end{array}$ \\
\hline EC07-02 & JUUL LABS & Juul & JUUL LABS & Virginia Tobacco & 0.052 & 0.33 & 1.633 & 6.7 & 85 & $\frac{13}{6.5}$ \\
\hline EC10-01 & VUSE & Alto & VUSE & Original & 0.052 & $N / R$ & 1.063 & 10.2 & 50 & 5 \\
\hline EC12-01 & SMOK & Novo 2 & MAD HATTER JUICE & Classic Tobacco & 0.039 & 0.44 & 1.463 & 7.4 & 58 & 8 \\
\hline EC14-01 & BLU & myblu & BLU & Classic Tobacco & 0.02 & 0.42 & 1.416 & 7.7 & 88 & 10 \\
\hline EC15-01 & NJOY & Ace & NJOY & Classic Tobacco & 0.05 & 0.48 & 1.034 & 10.5 & 58 & 5.5 \\
\hline EC16-01 & UWELL & Caliburn & MAD HATTER JUICE & Classic Tobacco & 0.039 & 0.44 & 1.405 & 7.8 & 88 & 10 \\
\hline EC17-01 & ASPIRE & Breeze 2 & MAD HATTER JUICE & Classic Tobacco & 0.039 & 0.44 & 0.631 & 17.3 & 30 & 10.5 \\
\hline EC18-01 & VAPOR4LIFE & V4L Titan & VAPOR4LIFE & Wowbacco & 0.023 & 0.73 & 2.258 & 4.8 & 50 & 10 \\
\hline EC19-01 & LOGIC VAPES & Logic Pro & LOGIC VAPES & Tobacco & 0.016 & 0.77 & 2.443 & 4.5 & 48 & 12 \\
\hline $\mathrm{EC} 20-01$ & LOONTECH & Hyde Original & LOONTECH & Spearmint & 0.061 & $\mathrm{~N} / \mathrm{R}$ & 1.61 & 6.8 & 86 & 10 \\
\hline EC22-01 & VUSE & Vibe & VUSE & Original Tobacco & 0.03 & 0.23 & 2.693 & 4.0 & 68 & 6 \\
\hline EC23-01 & SMOK & Stick Prince & MAD HATTER JUICE & Classic Tobacco & 0.052 & 0.44 & 0.174 & 62.6 & 90 & \\
\hline EC24-01 & PUFF BAR & Puff Bar & PUFF BAR & Tobacco & 0.049 & 0.54 & 1.688 & 6.5 & 50 & 3.6 \\
\hline
\end{tabular}

Notes: (1) Power was not experimentally measured in this investigation. Maximum nominal power was, for relative comparison only, computed from $P_{\text {Nom }}=V_{\text {Nom }}^{2} / R_{\text {Coil }}$ where $V_{\text {Nom }}$ was set to a constant value of $3.3[\mathrm{VDC}]$.

\subsection{Empicial TPM Yield Emission Model}

An empirical emission model of the TPM yield per puff is defined herein as the product of logistic (sigmoid) functions of puff flow rate and puff duration as shown in Equation (1a), identically zero below MinAF and MinAD as given by Equation (1b), and limited to the boundary condition above MaxAF and MaxAD as defined by Equations (1c), (1d) and (1e), consistent with a constant surface extrapolation: 


$$
\begin{aligned}
& \hat{Y}_{T P M}=\frac{1}{\min \left(\mathrm{B}_{1}, \mathrm{~B}_{4}\right)}\left(\frac{\mathrm{B}_{1}}{1+e^{-B_{2}\left(q-B_{3}\right)}}\right)\left(\frac{\mathrm{B}_{4}}{1+e^{-B_{5}\left(d-B_{6}\right)}}\right) \forall \operatorname{MinAF} \leq \mathrm{q} \leq \operatorname{MaxAF} ; \operatorname{MinAD} \leq \mathrm{d} \leq \operatorname{MaxAD} \\
& \widehat{Y}_{T P M}=0 \\
& \forall \mathrm{q}<\operatorname{MinAF} ; \mathrm{d}<\operatorname{MinAD} \\
& \hat{Y}_{T P M}=\frac{1}{\min \left(\mathrm{B}_{1}, \mathrm{~B}_{4}\right)}\left(\frac{\mathrm{B}_{1}}{1+e^{-B_{2}\left(q-B_{3}\right)}}\right)\left(\frac{\mathrm{B}_{4}}{1+e^{-B_{5}\left(\operatorname{Max} A D-B_{6}\right)}}\right) \forall \operatorname{MinAF} \leq \mathrm{q} \leq \operatorname{MaxAF} ; \mathrm{d}>\operatorname{MaxAD} \\
& \hat{Y}_{T P M}=\frac{1}{\min \left(\mathrm{B}_{1}, \mathrm{~B}_{4}\right)}\left(\frac{\mathrm{B}_{1}}{1+e^{-B_{2}\left(\operatorname{Max} A F-B_{3}\right)}}\right)\left(\frac{\mathrm{B}_{4}}{1+e^{-B_{5}\left(d-B_{6}\right)}}\right) \forall \mathrm{q}>\operatorname{MaxAF} ; \operatorname{MinAD} \leq \mathrm{d} \leq \operatorname{MaxAD} \\
& \hat{Y}_{T P M}=\frac{1}{\min \left(\mathrm{B}_{1}, \mathrm{~B}_{4}\right)}\left(\frac{\mathrm{B}_{1}}{1+e^{-B_{2}\left(\operatorname{MaxAF}-B_{3}\right)}}\right)\left(\frac{\mathrm{B}_{4}}{1+e^{-B_{5}\left(\operatorname{Max} A D-B_{6}\right)}}\right) \forall \mathrm{q}>\text { MaxAF; d }>\text { MaxAD }
\end{aligned}
$$

where $B_{3}$ and $B_{6}$ are the centroids of the logistic function of puff flow rate and duration, respectively, $\mathrm{B}_{2}$ and $\mathrm{B}_{5}$ are the logistic growth rates for puff flow rate and duration, respectively, $\mathrm{B}_{1}$ and $\mathrm{B}_{4}$ are the maximum model response for puff flow rate and duration, respectively, and $\hat{Y}_{T P M}$ is the model-predicted value of the yield per puff given a puff flow rate, $q$, and duration, $d$. The leading quotient permits the maximum TPM yield to be limited either by flow rate or by puff duration, appropriate to the observed response of each ENDS. The model is $\mathrm{C}_{0}$ continuous, guarantees the $\hat{Y}_{T P M}$ surface remains flat at long durations, $\mathrm{d}>\operatorname{MaxAD}$, when the coil becomes de-energized, and the mass concentration $\mathrm{C}_{\text {TPM }}$ decays with increasing puff volume above MaxAD and MaxAF. Using the experimental methods described previously, [2] an L-vector of YтPм observations was collected as a function of MinAF $<\mathrm{q}<$ MaxAF while $d$ was held constant and another M-vector of $Y_{T P M}$ observations as a function of MinAD $<\mathrm{d}<$ MaxAD while q was held constant, for a total of $\mathrm{L}+\mathrm{M}$ data points. The unweighted Levenberg-Marquardt nonlinear least squares algorithm [8] [9] was used to estimate the parameters $B_{1}$ through $B_{6}$ for each ENDS investigated. Coefficients $B_{1}$ through $B_{3}$ were determined by nonlinear regression of the "activation flow rate" data while $\mathrm{B}_{4}$ through $\mathrm{B}_{6}$ were determined by nonlinear regression of the "activation duration" data. The product of the two regression formulas, Equations (1), was then used to compute the sum of the squared residuals between the experimental observations and the hybrid model predictions:

$$
S S R=\sum_{i=1}^{L+M}\left(Y_{T P M}-\hat{Y}_{T P M}\right)^{2} .
$$

The initial guesses, $\mathrm{B}_{0}$, for the parameters to initialize the nonlinear least squares algorithm were taken to be: $\mathrm{B}_{0,1}=\max \left(\mathrm{Y}_{\mathrm{TPM}}\right)$ from the "activation flow rate" series, $\mathrm{B}_{0,2}=16 \pi /\left(\right.$ MaxAF-MinAF), $\mathrm{B}_{0,3}=$ MinAF + 0.1 (MaxAF-MinAF), $\mathrm{B}_{0,4}=\max \left(\mathrm{Y}_{\mathrm{TPM}}\right)$ from the "activation duration rate" series, $\mathrm{B}_{0,5}=\pi /($ MaxAD-MinAD), and $\mathrm{B}_{0,6}=\operatorname{MinAD}+0.5$ (MaxAD-MinAD).

\subsection{Empirical TPM Concentration Emission Model}

In addition to quantifying mass yield per puff of TPM, the model may be used to quantify the mass concentration of aerosol, denoted $\hat{C}_{T P M}$. The mass concentration is yield per puff normalized by the volume of the puff, Equation (3):

$$
\hat{C}_{T P M}(q, d)=\frac{\hat{Y}_{T P M}(q, d)}{q \cdot d}
$$

\subsection{Empirical Nicotine Mass Fraction Model}

The constituent mass ratio of nicotine, or any other aerosol constituent of interest, may be dependent upon operating parameters such as coil power, temperature, and e-liquid composition in addition to user topography as shown in Equation (4). Investigating the mass ratio of constituents as a function of flow conditions enables research laboratories to leverage the work of one another. For the 13 ENDS studied herein, fNic was determined to be independent of flow rate and duration, and the ENDS devices had no user adjustable parameters, such as power. Therefore, the nicotine mass ratio 
surface was simplified to the mean of the empirical observations of the nicotine mass ratio observed in the aerosol samples:

$$
\hat{f}_{N i c}=B_{7}+B_{8} q+B_{8} q+B_{10} q d+\cdots \approx \bar{f}_{N i c}
$$

\subsection{Empirical Nicotine Yield Model}

The nicotine yield per puff was estimated as a separable model of the nicotine mass ratio and the TPM yield per puff using an implicit assumption of linear superposition. For the current family of products tested the nicotine mass ratio was observed independent of flow rate and duration as shown in Eq. (5):

$$
\hat{Y}_{N i c}(q, d)=\hat{f}_{N i c}(q, d) \hat{Y}_{T P M}\left(q_{n}, d_{n}\right) \approx \hat{f}_{N i c} \hat{Y}_{T P M}\left(q_{n}, d_{n}\right)
$$

\subsection{Confidence Intervals on the Model Estimates}

The standard error of the regression, SYтPM, is a measure of the agreement between the model predicted values, $\hat{Y}_{T P M}$, and the $\mathrm{L}+\mathrm{M}$ experimental observations, $Y_{T P M}$, given by [10]

$$
S_{Y T P M}=\frac{1}{(L+M)} \sum_{i=1}^{L+M}\left(Y_{T P M}-\hat{Y}_{T P M}\right)^{2} .
$$

We estimated the $95 \%$ confidence interval on the estimate of TPM yield per puff as being $\varepsilon_{\text {YTPM }} \approx$ \pm 1.96 SYTPM, and similarly estimated the uncertainty in the estimate of the TPM mass concentration, $\mathrm{C}_{\mathrm{TPM}}$, as $\varepsilon_{\mathrm{CTPM}} \approx \pm 1.96 \mathrm{~S}_{\mathrm{CTPM}}$; nicotine mass ratio, $\mathrm{f}_{\mathrm{Nic}}$ as $\varepsilon_{\mathrm{FNic}} \approx \pm 1.96 \mathrm{~S}_{\mathrm{FNic}}$; and nicotine yield as $\varepsilon_{\mathrm{YNic}} \approx$ \pm 1.96 SyNic. Each quantity for the standard error of the regression was computed for the actual number of empirical observations across flow rate, $\mathrm{q}$, and duration, $\mathrm{d}$, for the respective outcome measure. For example, the number of observations of $f_{\text {Nic }}$ may differ from those of $Y_{\text {Nic. This }}$ approach was used as a means of assessing the impact of algebraic manipulation of the model, such as Equation (3), and validity of linear superposition assumption implied by Equation (5).

\subsection{Presentation of Results}

Several figures were generated for each ENDS screening emission model to illustrate the characteristics of the device. The first figure consisted of a scatter and regression plot of the "activation flow rate" data to assess the quality of parameters $B_{1}$ through $B_{3}$. The second figure was a scatter and regression plot of the "activation duration" data to assess the quality of parameters B4 through $\mathrm{B}_{6}$. The third figure consisted of a surface plot of the TPM yield per puff $\hat{Y}_{T P M}$ model predictions given by Equations (1) overlaid with the experimental data, $Y_{\text {TPM, }}$ as a function of puff flow rate, $q$, and duration, $d$. The fourth figure was a surface plot of the aerosol nicotine mass fraction, $\hat{f}_{N i c}$, given by Eq. (4), which was taken to be a flat surface for each of the 13 products investigated. The fifth figure generated for each ENDS device consisted of a surface plot of the TPM mass concentration, $\hat{C}_{T P M}=\hat{Y}_{T P M} /(\mathrm{q} \cdot \mathrm{d})$, model predictions overlaid with the experimental data, $\mathrm{C}_{\text {трм. }}$. The sixth figure consisted of the nicotine yield per puff using Equation (5). Each model is described in terms of the six parameters $\mathrm{B}_{1}-\mathrm{B}_{6}, \mathrm{p}$ values on each, coefficient of determination, $\mathrm{R}^{2}$, and the $95 \%$ confidence interval on the regression for each of the activation flow rate and activation duration series. The accuracy of the surface models of $Y_{\text {TPM }}, C_{\text {TPM }}$ and $Y_{\text {Nic }}$ were quantified as the 95\% confidence interval for the model computed from the corresponding standard error of regression analogous to Equation (6). All figures and details associated with each product tested are presented as supplemental data accompanying this article.

The screening emissions model of each device was summarized in a table, appropriate for use in other computer programs. The peak values of each response surface were determined and denoted as Max $\hat{Y}_{T P M}$, Max $\hat{C}_{T P M}$, Max $\hat{f}_{N i c}$, and Max $\hat{Y}_{N i c}$. This summary information for each product was then compiled into a "screening emissions model dashboard" to foster quantitative relative comparison of emissions between products. 


\subsection{Investigation of Association between Product Characteristics and Emissions Characteristics}

Each of the four emissions characteristics (Max $\hat{Y}_{T P M}$, Max $\hat{C}_{T P M}$, Max $\hat{f}_{N i c}$, and Max $\hat{Y}_{N i c}$ ) was separately evaluated using multi-variate linear regression to assess potential correlation between emissions and the product design and operating envelope characteristics listed in Table 2 as indicated by Equation (7)

$$
\operatorname{Max} \hat{Y}_{T P M}=\beta_{0}+\beta_{1} f_{N i c, E L i q}+\beta_{2} f_{P G, E L i q}+\beta_{3} R_{C o i l}+\beta_{4} \operatorname{MaxP}_{N o m}+\beta_{5} \operatorname{MaxAF}+\beta_{6} \operatorname{MaxAD} .
$$

The six linear regression coefficients were computed using QR decomposition [11] including M-estimation to formulate estimating equations [12] which were solved using the method of iteratively reweighted least squares [13] [14] as implemented in the commercially available fitlm package [9]. The value of each regression coefficient, $\beta$, and its corresponding sum of squared errors, SSE, test statistic and $p$ value were reported. The model (7) implicitly assumes the solvent is a binary mixture of propylene glycol and glycerin characterized by a single parameter, $\mathrm{fPG}$, with nicotine added to the un-puffed E-Liquid reported as a mass ratio fNicELiq. More complex solvents would require additional characterization parameters. The mean value of coil resistance, $R$ coil, was taken from the previous report, as were the operating envelope parameters MaxAF and MaxAD.

The actual transient power was not measured for these experimental conditions. A constant voltage of $\mathrm{V}_{\mathrm{Nom}}=3.3$ [VDC] was assumed as a basis for conducting relative nominal maximum power comparisons between products. The maximum relative nominal power dissipated was determined using Equation (8):

$$
\operatorname{Max} P_{\text {Nom }} \equiv \frac{V_{\text {Nom }}^{2}}{R_{\text {Coil }}}
$$

Equation (8) neglects any active control (such as constant voltage, constant current, or pulse modulation) which may be employed in the Power Control Unit of the product. While not an accurate representation of the true power dissipated in the coil, the maximum nominal power is a reasonable method for conducting a first order quantitative comparison between products, and is representative of the maximum nominal power anticipated for the product.

After each multi-variate linear regression, similar to Eq. (7), was established for each of the four emissions characteristics an added variable assessment based on the Frisch-Waugh-Lovell theorem [15] of each product characteristic was conducted to determine whether each adjusted product characteristic exhibited an effect on the adjusted emission characteristic which was statistically distinguishable from the mean adjusted response within 95\% confidence bounds. Those product characteristics observed to be significant were recommended for regulatory consideration.

\section{Results}

\subsection{Exemlpary Results for One Product}

An exemplary sequence of six figures for a single product (EC14-01 BLU myBlu PCU with BLU Classic Tobacco E-Liquid) are presented to illustrate the methods employed. A summary table of model parameters and fit quality estimates will be presented. Figure 1 shows the experimental data (markers) for TPM yield per puff as a function of flow rate while the nominal puff duration was held constant. The logistic regression model described by parameters $\mathrm{B}_{1}, \mathrm{~B}_{2}, \mathrm{~B}_{3}$ is shown as the solid line, while the $95 \%$ confidence interval on the regression is shown as dashed lines. Product EC14-01 exhibits a distinct minimum flow rate below which the coil does not activate and above which the coil consistently energizes. 


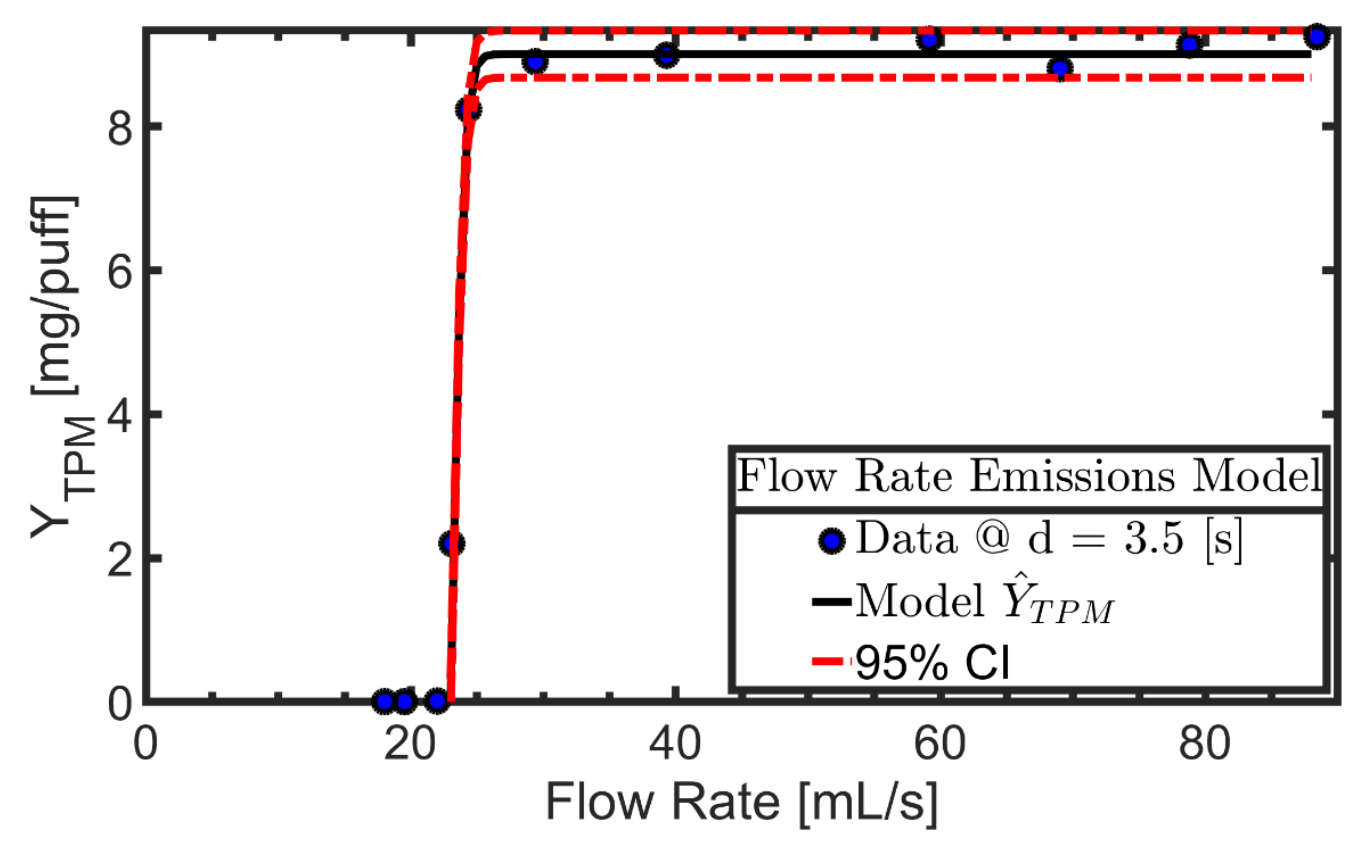

Figure 1. Product EC14-01. TPM yield per puff observed during 'Activation Flow Rate' screening trials conducted with nominal puff duration of 3.5 [s] and puff flow rate varying from 23 to 88 $[\mathrm{mL} / \mathrm{s}]$. The nonlinear regression emissions model (solid line) and 95\% confidence interval (dashed line) are illustrated.

Figure 2 shows the experimental data (markers) for TPM yield per puff as a function of duration while the nominal puff flow rate was held constant. The logistic regression model described by parameters $B_{4}, B_{5}, B_{6}$ is shown as the solid line, while the $95 \%$ confidence interval on the regression is shown as dashed lines. Product EC14-01 exhibits a nonlinear relationship between TPM yield and puff duration, and the coil was observed to remain energized at least until 10 [s] puff duration, the maximum duration investigated here.

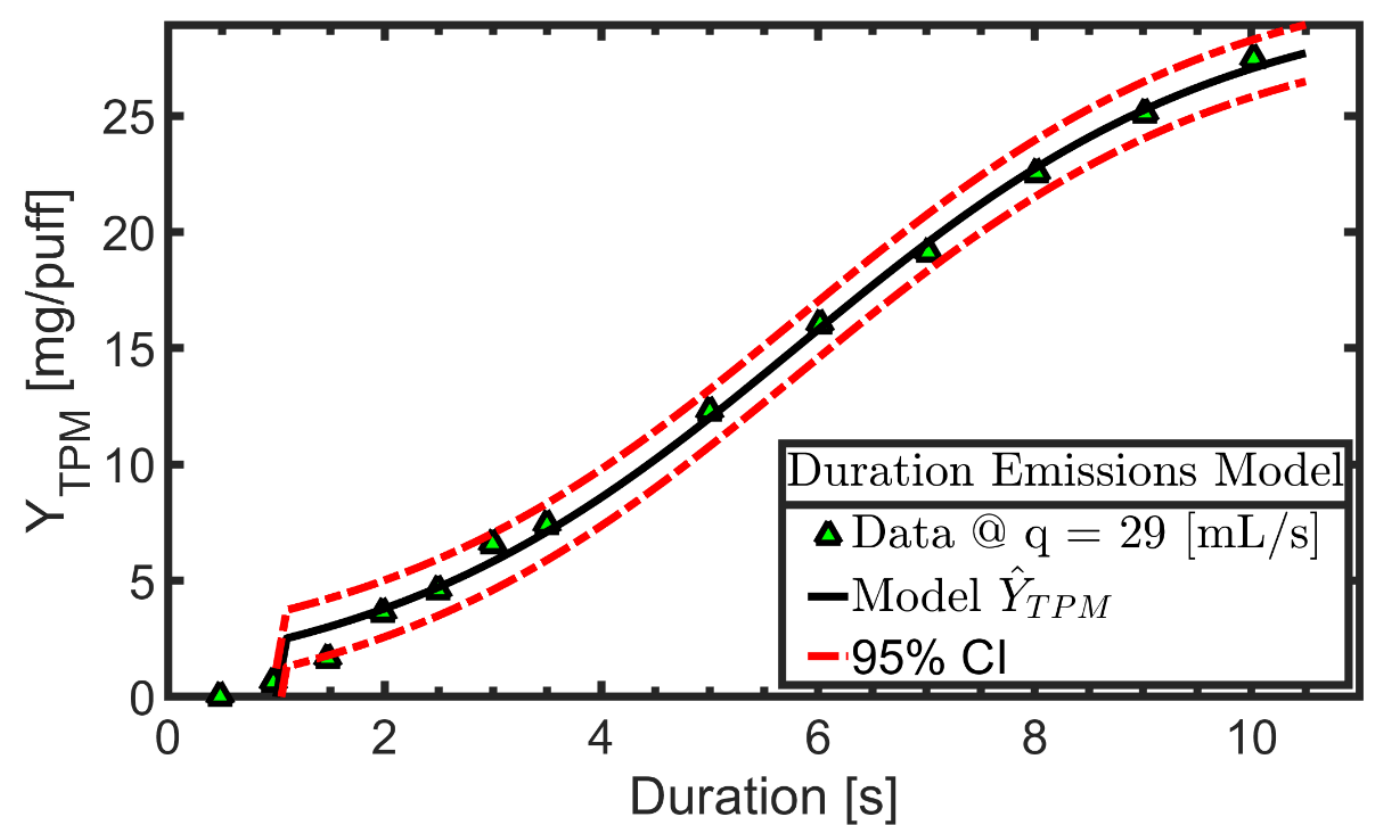

Figure 2. Product EC14-01. TPM yield per puff observed (markers) during 'Activation Duration' screening trials conducted with nominal puff flow rate of $29[\mathrm{~mL} / \mathrm{s}]$ and puff duration varying from 1.0 to $10[\mathrm{~s}]$. The nonlinear regression emissions model (solid line) and 95\% confidence interval (dashed line) are illustrated. 
Figure 2 shows the hybrid emissions screening model for TPM yield per puff, $\hat{Y}_{T P M}$, as a function of flow rate and duration with the surface as defined by Equations (1a) through (1e). The underlying data is illustrated by the markers, while the semi-transparent surfaces reflect the $95 \%$ confidence interval, EYTPM, associated with the standard error of the regression, SYTPM, given by Equation (6). The value of Max $\hat{Y}_{T P M}$ was observed to be $23.3 \pm 2.71$ [mg/puff] for product EC14-01.

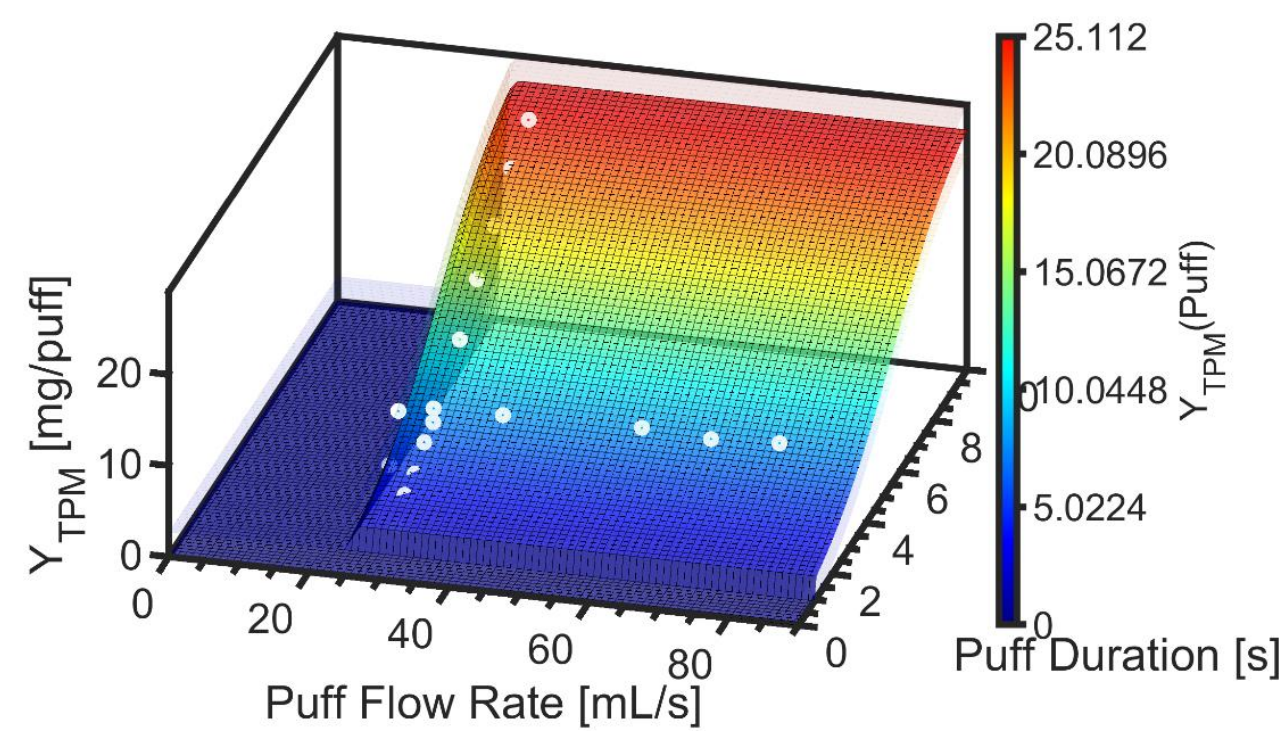

Figure 3. Product EC14-01. Screening Emissions model for TPM yield per puff is illustrated as the colored surface plot, with semi-transparent surfaces above and below the model surface to reflect the $95 \%$ confidence interval on the nonlinear regression. Underlying data is illustrated with markers.

Figure 2 shows the hybrid emissions screening model for TPM mass concentration as a function of flow rate and duration with the surface as defined by Equation (3). The underlying data is illustrated by the markers, while the semi-transparent surfaces reflect the $95 \%$ confidence interval, عстрм. The value of Max $\hat{C}_{T P M}$ was observed to be $0.110 \pm 0.023[\mathrm{mg} / \mathrm{mL}]$ for product EC14-01.

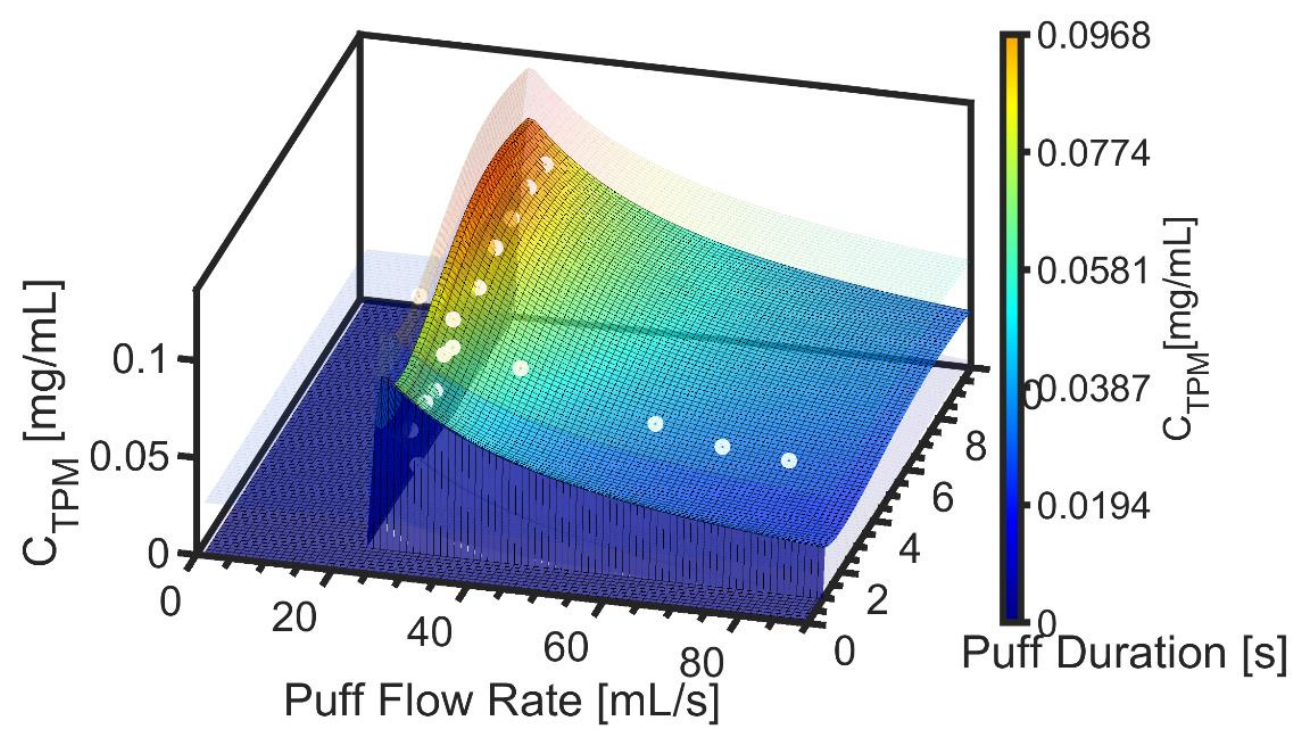

Figure 4. Product EC14-01. Screening Emissions model for TPM mass concentration is illustrated as the colored surface plot, with semi-transparent surfaces above and below the model surface to reflect the $95 \%$ confidence interval on the nonlinear regression. Underlying data is illustrated with markers. 
Figure 2 illustrates that no statistically significant dependence of $f_{\mathrm{Nic}}$ was observed as a function of puff flow rate or duration. While true for all 13 products tested here, the method permits topography dependence of all constituents. In general, a multivariate model such as that shown by Equation (4) may be more appropriate. The underlying data is illustrated by the markers, while the semi-transparent surfaces reflect the $95 \%$ confidence interval, $\varepsilon$ fNic. The value of Max $\hat{f}_{\text {Nic }}$ was observed to be $0.024 \pm 0.005$ [mg Nic/mg TPM] for product EC14-01.

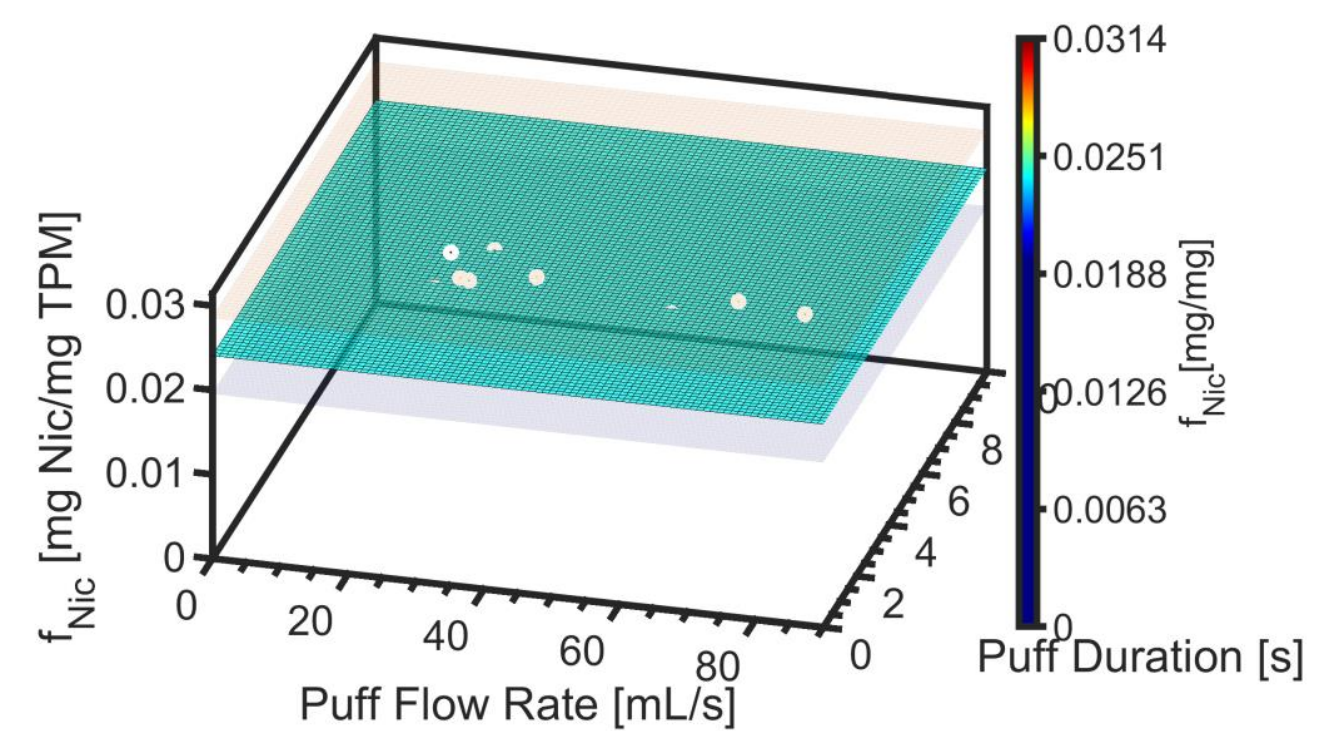

Figure 5. Product EC14-01. Screening Emissions model for nicotine mass ratio is illustrated as the colored surface plot, with semi-transparent surfaces above and below the model surface to reflect the $95 \%$ confidence interval on the nonlinear regression. Underlying data is illustrated with markers.

Figure 2 shows nicotine yield per puff, $\hat{Y}_{N i c}$, as a function of flow rate and duration as defined by Equation (5). The shape of the surface is identical to $\hat{Y}_{T P M}$ because the nicotine mass ratio was observed to be independent of puff topography. For constituents not having a uniform mass ratio, fHPHC, the shape of the $\hat{Y}_{H P H C}$, surface shape will differ from that of TPM yield. The underlying data is illustrated by the markers, while the semi-transparent surfaces reflect the $95 \%$ confidence interval, $\varepsilon$ YNic. The value of Max $\hat{Y}_{N i c}$ was observed to be $0.634 \pm 0.081$ [mg/puff] for product EC14-01.

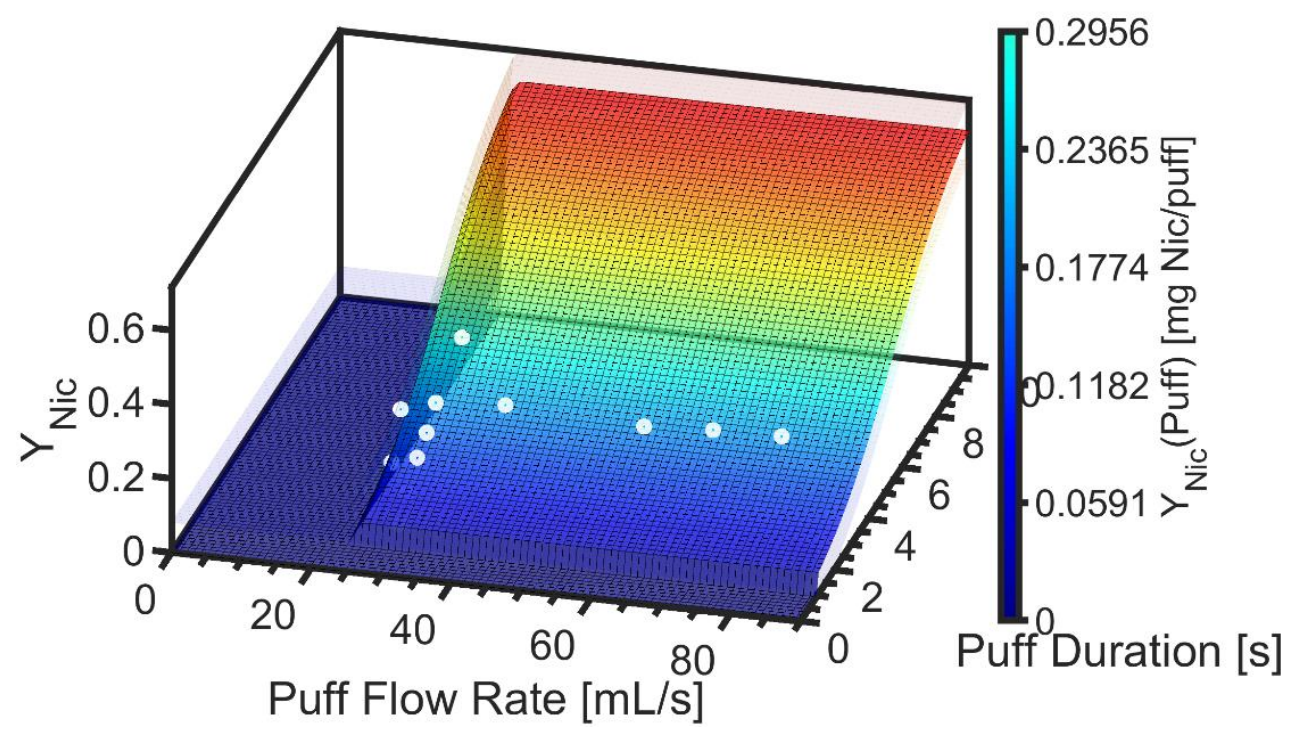

Figure 6. Product EC14-01. Screening Emissions model for nicotine yield delivered to the mouth as a function of puff flow rate and duration is illustrated as the colored surface plot, with 
semi-transparent surfaces above and below the model surface to reflect the $95 \%$ confidence interval on the nonlinear regression. Underlying data is illustrated with markers.

\subsection{Summative Results for Quantitative Comparison of all 13 Products}

The maximal response point of the emissions screening model for each of the thirteen products tested is shown in Table 3. The values of maximum TPM yield per puff varied widely, from 2.21 up to 90.94 [mg/puff], with similar variations in TPM mass concentration from 0.028 to 0.651 [mg/mL] and nicotine yield per puff from 0.101 to 4.175 [mg/puff]. The underlying data for all model coefficients, $\mathrm{p}$ values, SSR, $\mathrm{R}^{2}$, and additional model parameters is available in the supplemental data accompanying this article.

Table3. Maximal emissions characteristics for 13 Pen and Pod style Electronic Nicotine Delivery Systems.

\begin{tabular}{|c|c|c|c|c|c|c|c|c|}
\hline $\begin{array}{l}\text { Product } \\
\text { ID } \\
\text { Code }\end{array}$ & $\begin{array}{l}\text { Device } \\
\text { Manufacturer }\end{array}$ & $\begin{array}{l}\text { Device } \\
\text { Model }\end{array}$ & $\begin{array}{l}\text { Consumable } \\
\text { Manufacturer }\end{array}$ & $\begin{array}{l}\text { Consumable } \\
\text { Labeled } \\
\text { Flavor }\end{array}$ & $\begin{array}{l}\text { Max } \\
Y_{T P M} \\
\text { [mg/puff] }\end{array}$ & $\begin{array}{l}\text { Max } \\
C_{T P M} \\
{[\mathrm{mg} / \mathrm{mL}]}\end{array}$ & $\begin{array}{l}\text { Max } \\
f_{\text {Nic }} \\
{[\mathrm{mg} / \mathrm{mg}]}\end{array}$ & $\begin{array}{l}\text { Max } \\
Y_{N i c} \\
{[\mathrm{mg} / \text { puff] }}\end{array}$ \\
\hline EC07-02 & JUUL LABS & Juul & JUUL LABS & Virginia Tobacco & 2.210 & 0.028 & 0.046 & 0.101 \\
\hline EC10-01 & VUSE & Alto & VUSE & Original & 11.433 & 0.061 & 0.046 & 0.531 \\
\hline EC12-01 & SMOK & Novo 2 & MAD HATTER JUICE & Classic Tobacco & 12.814 & 0.057 & 0.051 & 0.650 \\
\hline EC14-01 & BLU & myblu & BLU & Classic Tobacco & 26.341 & 0.110 & 0.024 & 0.634 \\
\hline EC15-01 & NJOY & Ace & NJOY & Classic Tobacco & 11.790 & 0.190 & 0.056 & 0.663 \\
\hline EC16-01 & UWELL & Caliburn & MAD HATTER JUICE & Classic Tobacco & 12.193 & 0.167 & 0.046 & 0.565 \\
\hline EC17-01 & ASPIRE & Breeze 2 & MAD HATTER JUICE & Classic Tobacco & 10.911 & 0.300 & 0.039 & 0.424 \\
\hline EC18-01 & VAPOR4LIFE & V4L Titan & VAPOR4LIFE & Wowbacco & 6.365 & 0.094 & 0.030 & 0.188 \\
\hline EC19-01 & LOGIC VAPES & Logic Pro & LOGIC VAPES & Tobacco & 20.911 & 0.276 & 0.020 & 0.412 \\
\hline EC20-01 & LOONTECH & Hyde Original & LOONTECH & Spearmint & 16.714 & 0.114 & 0.061 & 1.015 \\
\hline EC22-01 & VUSE & Vibe & VUSE & Original Tobacco & 8.998 & 0.077 & 0.031 & 0.276 \\
\hline EC23-01 & SMOK & Stick Prince & MAD HATTER JUICE & Classic Tobacco & 90.943 & 0.651 & 0.046 & 4.175 \\
\hline EC24-01 & PUFF BAR & Puff Bar & PUFF BAR & Tobacco & 5.343 & 0.288 & 0.049 & 0.260 \\
\hline
\end{tabular}

The emissions model screening results are presented graphically as interval plots in Figure 7. The results are sorted using the upper bound on the confidence interval for each parameter to compare each of the maximal emissions characteristics between products. This approach was chosen to illustrate the (i) combined effects of sample size and underlying product variation, (ii) desire to conduct comparisons using the most severe exposure scenario capable of being experienced by users of the product, and (iii) inform natural groupings for holistic 'dashboard' comparisons

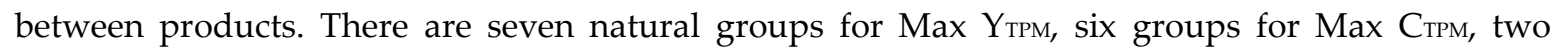
groups for Max $\mathrm{f}_{\mathrm{Nic}}$, and five groups for Max $\mathrm{Y}_{\mathrm{Nic}}$ for the family of 13 products tested here. The results for product EC23-01 are off-scale for Max $\mathrm{Y}_{\text {тPм }}$ and Max $\mathrm{Y}_{\text {Nic. }}$ 

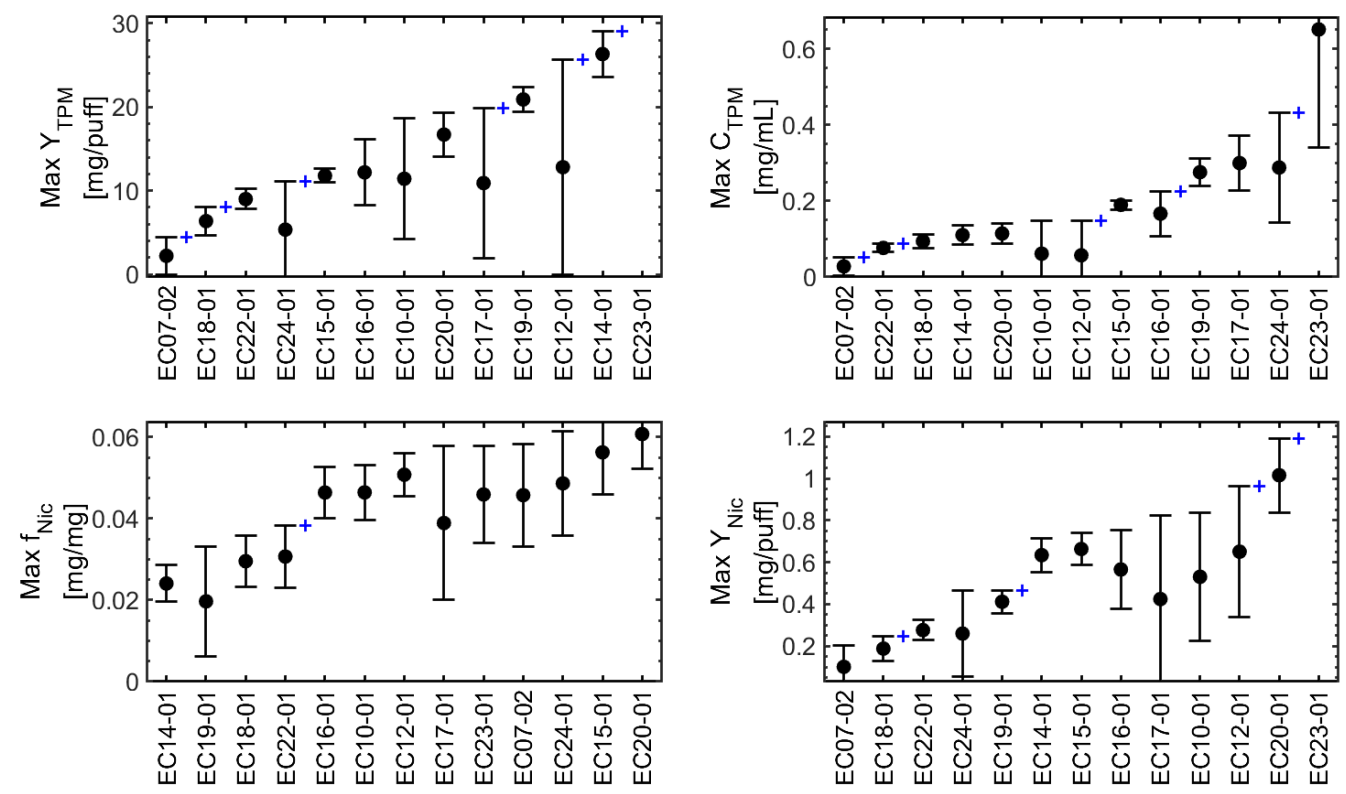

Figure 7. Interval plot for the maximal emissions characteristics demonstrating quantitative comparison between products. Results are sorted within each figure in order of increasing maximal value plus the upper $95 \%$ confidence bound from left to right. The ' + ' marker between successive data points indicates there is a significant difference between maximal product emissions $(\mathrm{p}<0.05)$.

Table 4 presents the lowest five statistically significant differences between maximal emissions characteristics presented in Figure 7. Only two significant levels for the aerosol mass ratio f Nic were observed among the products tested. As additional E-Liquid concentrations are tested, the number of $f_{\text {Nic }}$ levels may be increased to reflect observed variation in this emission characteristic.

Table 4. The lowest five statistically significant differences between maximal emissions characteristics observed across the thirteen product combinations tested.

\begin{tabular}{ccccccccc} 
Factor & \multicolumn{2}{c}{$\begin{array}{c}\text { Max YTPM } \\
\text { [mg/puff] }\end{array}$} & \multicolumn{2}{c}{$\begin{array}{c}\text { Max CTPM } \\
{[\mathrm{mg} / \mathrm{mL}}\end{array}$} & \multicolumn{2}{c}{ Max fic } \\
Level & Lower & Upper & Lower & Upper & Lower & Upper & Lower & Max Y \\
[mic & Upper \\
\hline 1 & 0.0 & 4.46 & 0.0 & 0.052 & 0.0 & 0.038 & 0.0 & 0.249 \\
2 & 4.46 & 8.03 & 0.052 & 0.087 & & & 0.249 & 0.465 \\
3 & 8.03 & 11.06 & 0.087 & 0.148 & & & 0.465 & 0.962 \\
4 & 11.06 & 19.9 & 0.148 & 0.226 & & & 0.962 & 1.192 \\
5 & 19.9 & inf & 0.226 & inf & 0.038 & inf & 1.192 & inf
\end{tabular}

A proposed product emissions dashboard is presented in Figure 8. The dashboard is intended to provide an informational graphic which may be appealing to consumers, similar to dashboards about community pandemic risk levels, terror alert levels, or consumer product benchmark comparisons. Each row of the dashboard uses up to five color indicators reflecting the statistically significant levels of each factor presented in Table 4. 


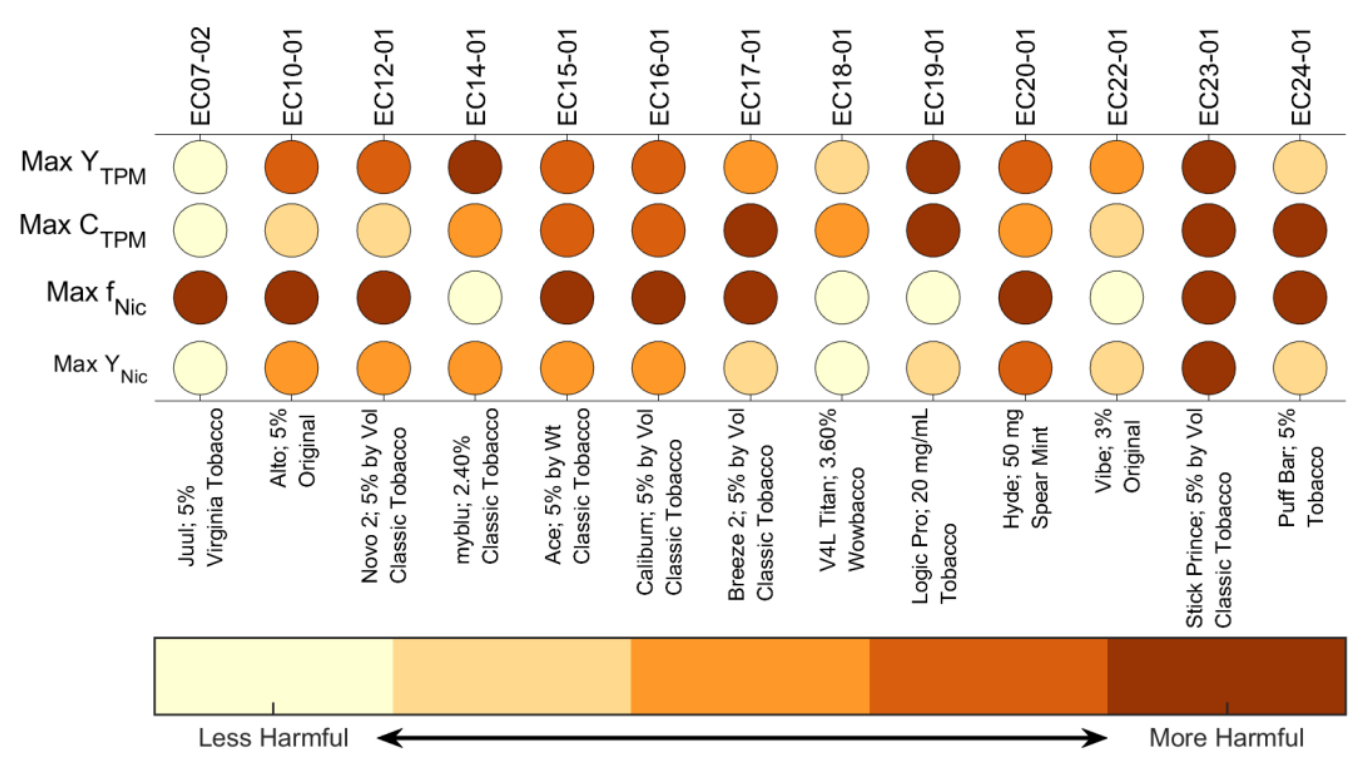

Figure 8. Maximal emissions screening dashboard for consumer-oriented comparisons between tobacco products. The horizontal axis indicates the ENDS device model, consumable labeled nicotine concentration, and flavor brand name for cross-reference to Table 2 and 3.

Observe the Max $\mathrm{Y}_{\mathrm{Nic}}$ of products EC14-01, EC19-01 and EC22-01 were significantly larger than that of EC07-02, even though the aerosol nicotine mass ratio, $\mathrm{f}_{\mathrm{Nic}}$, and branded nicotine concentration of the corresponding e-liquids were significantly lower. The relatively higher values of both Мах Үтрм and Max CTPM associated with product EC14-01, EC19-01 and EC22-01 resulted in higher maximum nicotine yield to the mouth than product EC07-02. Users of those products will be exposed to significantly more TPM for a given cumulative daily consumption of nicotine.

\subsection{Association Between Tobacco Product Emissions and Product Characteristics}

The next set of results investigated whether associations exist between maximum achievable emissions characteristics (what is delivered to the mouth of a user) and the underlying tobacco product characteristics (the design, composition and operation of the tobacco product). This information is essential for prioritizing proposed regulated product characteristics. As one exemplar analysis, multivariate linear regression was used to investigate possible associations between the maximum TPM yield per puff delivered to the mouth of a user, Max $\hat{Y}_{T P M}$, and the product design characteristics presented in Table 2. The results are illustrated in Figure 9.

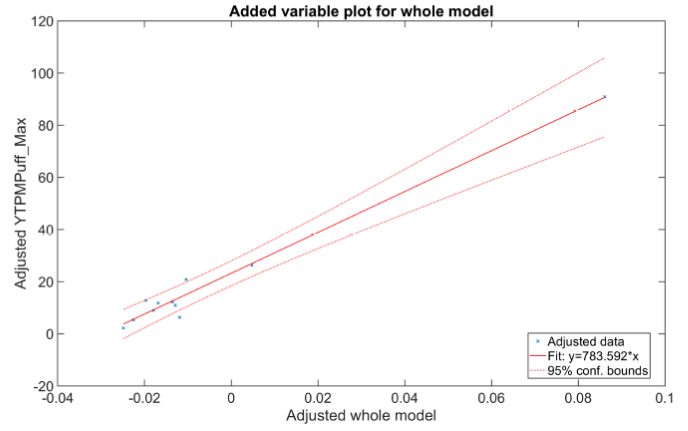

\begin{tabular}{lrrr}
\hline Estimated Coefficients: & Estimate & SE & tStat \\
\hline (Intercept) & 23.229 & 28.23 & 0.8228 \\
MaxAF & 0.2516 & 0.1078 & 2.335 \\
MaxAD & -1.7727 & 1.355 & -1.3082 \\
$R$ Coil & -2.5472 & 5.000 & -0.5094 \\
Max $P_{\text {Nom }}$ & 1.4806 & 0.1667 & 8.882 \\
$f_{\text {Nic Unpuffed }}$ & -783.4 & 319.4 & -2.453 \\
PG Fraction & 17.098 & 15.16 & 1.128 \\
\hline \multirow{4}{*}{ Number of observations: 11} \\
Error degrees of freedom: 4 \\
Root Mean Squared Error: 5.62 \\
R-squared: 0.98, Adjusted R-Squared: 0.95 \\
F-statistic vs. constant model: 31.8, p-value $=0.00246$
\end{tabular}

Figure 9. Assessing potential associations between Max $\hat{Y}_{T P M}$ and the product characteristics of $\mathrm{f}_{\mathrm{Nic}}, \mathrm{fPG}_{\mathrm{PG}}$ RCoil, Max PNom, MaxAF, and MaxAD.

The maximum yield of TPM per puff was significantly associated with ENDS power $(\mathrm{p}<0.001)$ and somewhat inversely related to the E-Liquid nicotine concentration $\mathrm{f}_{\mathrm{Nic}}$ (un-puffed), $(\mathrm{p} \approx 0.056)$. Both associations are logical considering the physics of aerosolization. The presence of nicotine in the E-Liquid solution tends toward increasing the saturation temperature of the mixture, while 
increased power to the coil enables more heat and mass transfer. Similar assessments investigating the dependence of Max $\hat{C}_{T P M}$, Max $\hat{f}_{N i c}$, and Max $\hat{Y}_{N i c}$ are presented in the supplemental information accompanying this article.

The influence of each product characteristic on each adjusted emissions characteristic was assessed using added value plots, wherein the multi-variate linear model was evaluated for each adjusted product characteristic while holding the remaining product characteristics constant. This resulted in a matrix of 24 responses; four emissions characteristics and six product characteristics. The Frisch-Waugh-Lovell theorem [15] results are shown in Figure 10.
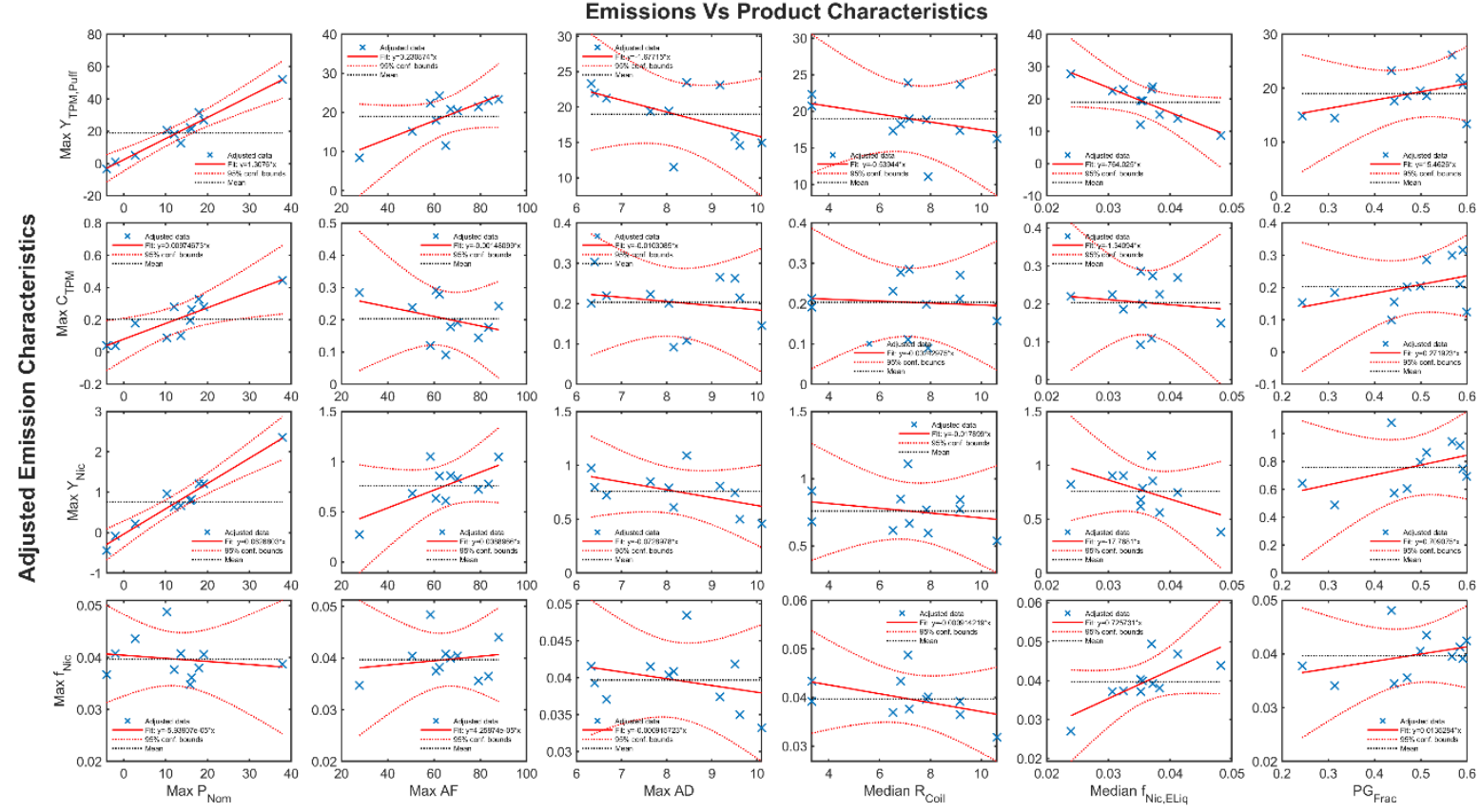

Adjusted Product Characteristics

Figure 10. Added variable assessment of each adjusted emission characteristic (Max $\hat{Y}_{T P M}$, Max $\hat{C}_{T P M}, \operatorname{Max}$ $\hat{f}_{N i c}$, and Max $\hat{Y}_{N i c}$ ) as a function of each adjusted product characteristic (Max PNom, MaxAF, MaxAD, Rcoil, $\left.\mathrm{f}_{\mathrm{Nic}}, \mathrm{fPG}_{\mathrm{P}}\right)$ while holding other product characteristics constant. Thirteen pod- and pen-style ENDS devices are represented in the data set.

Each panel of Figure $\mathbf{1 0}$ shows the linear regression best-fit association between one emissions characteristic (rows of the figure) and one product characteristic (columns of the figure). The discrete blue markers indicate the adjusted values of the emission and product characteristic while holding other product characteristics fixed. The solid line indicates whether an apparent positive or negative association exists, with the slope of the line indicated in each legend. The dashed red lines indicate the $95 \%$ confidence bounds on each association, and the black horizontal line indicates the mean of the adjusted emission response. If the black horizontal mean response line crosses the $95 \%$ confidence bounds then the product characteristic may be taken to be a viable indicator or predictor of the emission characteristic. Conversely, if the mean response line falls between the 95\% confidence bounds, then there exist an infinite number of associations which are statistically indistinguishable from the apparent association (the solid red line), and the product characteristic may not be taken to be a viable predictor of the emission characteristic. It is therefore asserted that the product characteristic of maximum nominal coil dissipation power, Max $\mathrm{P}_{\mathrm{Nom}}$, is a positively associated predictor of Max Y $\mathrm{Y}_{\text {TPM }}$ and Max $\mathrm{Y}_{\mathrm{Nic}}$ and a likely predictor of Max $\mathrm{C}_{\text {TPM. }}$. The remaining product characteristics, of $\mathrm{fNic}_{\mathrm{Ni}} \mathrm{fPG}_{\mathrm{PG}} \mathrm{R}_{\mathrm{Coil}}$, Min $\mathrm{AD}$ and Max $\mathrm{AD}$, taken individually, are not deemed to be viable predictors of emission characteristics. 


\section{Discussion}

\subsection{Key Findings of Regulatory Significance}

Regulating E-Liquid nicotine concentration alone is insufficient to limit the maximum yield of nicotine delivered to the mouth of a user. In fact, decreasing nicotine concentration in the E-Liquid while keeping all other product characteristics fixed will result in a net increase in TPM exposure for a user who consumes a given mass of nicotine per day. That is, a consumer who compensates their behavior $[16,17]$ to achieve a desired nicotine consumption will increase their TPM exposure.

Limiting the maximum power permitted in vaping devices is an effective product characteristic to be considered for regulation. The maximum power capable of being dissipated in the coil of a vaping product has a statistically significant positive correlation with maximum TPM yield per puff, Max $\mathrm{Y}_{\text {TPM, }}$ maximum TPM mass concentration in the aerosol, Max C $_{\text {TPM, }}$ and maximum nicotine yield per puff, Max $Y_{\text {Nic. }}$

Rather than limiting the design characteristics of tobacco products, it may be far more effective to regulate the maximum permissible emissions from the tobacco product. As an analogy to environmental regulations, limits are typically placed on the amount and concentration of effluents (emissions) leaving a factory and going into the environment. It is generally left up to the manufacturer to determine how to achieve the emissions targets. Conversely, it is virtually impossible to anticipate the complex interaction between device and consumable characteristics and regulating those design characteristics provides numerous opportunities for product manipulation to "design around" the regulations. It is more effective to regulate the actual end-goal of emissions.

It is insufficient to evaluate emissions under a single operating condition as a basis for comparison between products or to establish substantial equivalence between products. Emissions from tobacco products are dependent upon the puff flow rate, duration, E-Liquid composition, device design, and operating power of ENDS.

It is recommended that tobacco product applications for marketing approval require experimental characterization of the emissions from the product over the entire operating range of the product: Min $\mathrm{AD}<\mathrm{d}<\mathrm{Max} \mathrm{AD}$ and $\mathrm{Min} \mathrm{AF}<\mathrm{q}<\mathrm{Max} \mathrm{AF}$ at the maximum actual operating power of the product, Max $P_{\text {Actual. }}$

Tobacco product emission regulations should focus on direct emissions outcome measures in an effort to make regulations insensitive to product design manipulations. Traditional product characteristics considered for regulation include items such as E-Liquid nicotine concentration and possibly coil resistance. However, such regulations may not achieve the desired public health outcomes. Even if ENDS manufacturers are constrained to a certain E-Liquid nicotine mass concentration, they are able to manipulate numerous product characteristics to achieve a high nicotine yield per puff: increase the PCU de-energize duration (Max AD), decrease the coil resistance (Rcoil), increase the coil voltage or current, increase the coil power duty cycle, (all manifest as Max P) decrease the ENDS flow path resistance, or modify the solvent saturation temperature (e.g., fPG). All of these manipulated product characteristics result in potentially adverse unintended public health consequences. We propose it is more effective to regulate the product characteristics of TPM (Max $\mathrm{Y}_{\text {TPM) }}$ ) and nicotine (Max $\mathrm{Y}_{\mathrm{Nic}}$ ) yield per puff. In the proposed case, manufacturers have free reign to manipulate numerous design parameters of their PCUs and E-Liquids, but the end-result outcome measure remains consistently regulated.

\subsection{Limitations and Scope}

The results presented herein may be limited to pen- and pod-style ENDS not having user adjustable power or flow-paths. The screening emissions model, outcome measures, and method for assessing association between emission characteristics and product characteristics may be broadly applied to a variety of inhaled tobacco products including ENDS, combustibles and heated tobacco products (also referred to as 'Heat Not Burn'). The methods may be extended to other Electronic Vaping Products (EVPs) with further development. 
This article has proposed a consumer-oriented dashboard (Figure 8) for quantitative comparison of ENDS devices and consumables. The dashboard may be combined with the list of product design characteristics (Table 2) as recommended starting point for consumer packaging requirements. The approach to comparison of maximal product emissions (Figure 7) is recommended as a basis for quantifying substantial equivalence of tobacco products.

Similar to the proposed rule to limit the nicotine permitted in combustible cigarettes [18] reducing maximum allowable nicotine concentration in E-Liquids may be suggested as a means of reducing the addictive potential of ENDS and the risk of initiating combustible cigarette use following use of ENDS [19] and reducing the probability of youth becoming newly addicted to nicotine [20]. The public health benefits of reducing nicotine dependence are well established [21].

However, for currently addicted users of nicotine, it is important to also assess the potential adverse unintended public health consequences which may be associated with increased TPM exposure arising from reduced nicotine concentration. The current work does not fully address the potential public health impacts of nicotine concentration regulation.

The relatively small number of unique power control units (PCUS) and reservoirs (pods or tanks) tested for each ENDS product, in conjunction with the limited number of repeated trials per flow condition, resulted in relatively large confidence intervals on the emissions surfaces. With additional trials, the confidence bounds may be reduced to permit a finer resolution comparison of maximal emissions between products. Even with the limited number of repeated trials reflected in the data sets presented, differences between products outweigh expected adjustments to the models which would result from collecting more data.

The maximum emissions characteristics (Max $\hat{Y}_{T P M}$, Max $\hat{C}_{T P M}, \operatorname{Max} \hat{f}_{N i c}$, and Max $\hat{Y}_{N i c}$ ) reflect the severe exposure limits capable of being experienced by users of the product within the normal use operating envelope of the product. Two questions arise regarding the validity of relying upon the extrema for emissions comparison. The first question is: do the maximum values represent actual exposures which will be experienced by user? A closely related question is: are there limits on the emissions model above which, while the device sill operates, would never be observed by actual product users? The answers to both questions lie in characterizing the natural environment use patterns documenting how each product is actually used, as outlined in the next section.

\subsection{Gaps Which Need to be Addressed}

A thorough understanding of user topography behavior in the natural environment is required to accurately model public health consequences of proposed product regulations. Studies to understand how users compensate both their short-term (puff and respiration topography) behavior and long-term (cumulative daily, weekly and annual consumption) behavior in response to changes in product characteristics are needed. Studies are needed to investigate how users' short- and long-term behavior changes (a) as they become more or less addicted, (b) when dual-using tobacco products, (c) in association with confounding factors such as alcohol use or illicit drug use, (d) with socio-economic status, (e) between under-represented groups, (f) among at-risk populations, (g) with mental health condition, and (h) by pregnancy or lactation status.

A better understanding of the dynamic power control methods employed in ENDS will be valuable for establishing a first-principles causal relationship between ENDS operating power and emissions characteristics. Studies are needed to assess the effect of operating power and ENDS product characteristics which may impact maximum coil operating temperature, and hence give rise to chemical decomposition by-products in aerosols.

Characterization of fConstituent for all compounds present in E-Liquids and ENDS Reservoirs and for all HPHCs identified in aerosols is needed. Studies are needed to fully identify and quantify all constituents in ENDS devices, consumables, and packaging. Studies of leach testing are needed to assess product degradation under normal and adverse storage and use conditions.

We recommend standardization of emission reporting outcome measures between laboratories as $\mathrm{Y}_{\text {TPM, }} \mathrm{C}_{\mathrm{TPM}}$, and f $\mathrm{fonstituent.}$ 


\section{Conclusions}

Three emissions outcome measures $(\mathrm{Y}, \mathrm{C}, \mathrm{f})$ are recommended for adoption as standard quantities for emissions testing and reporting by manufacturers and research laboratories.

A standard method for quantifying and comparing maximal emissions from ENDS products has been presented and demonstrated.

A product design characteristics table has been proposed for comparative evaluation of ENDS devices and consumables.

A product emissions dashboard has been proposed for comparative evaluation of ENDS exposure potential.

Maximum achievable power dissipated in the coil of ENDS is an effective regulatory parameter.

Acknowledgements: The authors thank B.T. Meyers and M. Thomas for their contributions to earlier aspects of this research effort.

Author Contributions: The authors' individual contributions included: conceptualization, E.C.H., R.J.R., N.C.E.; methodology, A.G.D., N.C.E. and E.C.H.; software, E.C.H.; validation, E.C.H. and R.J.R.; formal analysis, E.C.H.; investigation, N.C.E., A.G.D., S.E.S., S.J., Q.M.S., , E.C.H., and R.J.R.; resources, E.C.H. and R.J.R.; data curation, A.G.D., S.J., S.E.S., , and E.C.H.; writing-original draft preparation, E.C.H.; writing-review and editing, R.J.R.,N.C.E.; visualization, E.C.H.; supervision, E.C.H. and R.J.R.; project administration, E.C.H. and R.J.R.; funding acquisition, E.C.H., R.J.R., and N.C.E. All authors have read and agreed to the published version of the manuscript.

Funding: Research reported in this publication was supported by the National Institute Of Environmental Health Sciences (NIEHS) of the National Institutes of Health and FDA Center for Tobacco Products (CTP) under Award Number R21ES029984. The content is solely the responsibility of the authors and does not necessarily represent the official views of the NIH or the Food and Drug Administration.

Conflicts of Interest: None of the authors have any conflicts of interest to declare.

\section{References}

1. Son, Y.; Bhattarai, C.; Samburova, V.; Khlystov, A. Carbonyls and Carbon Monoxide Emissions from Electronic Cigarettes Affected by Device Type and Use Patterns. International Journal of Environmental Research and Public Health 2020, 17, doi:10.3390/ijerph17082767.

2. Hensel, E.C.; Eddingsaas, N.C.; Saleh, Q.M.; Jayasekera, S.; Sarles, S.E.; Thomas, M.; Myers, B.T.; DiFrancesco, A.G.; Robinson, R.J. Nominal Operating Envelope of Pod and Pen Style Electronic Cigarettes. Frontiers in Public Health 2021, 9, 1201, doi:https://dx.doi.org/10.3389\%2Ffpubh.2021.705099.

3. ISO/TC-126/SC-3. ISO 20768:2018 Vapour product - Routine analytical vaping machine - definitions and standard conditions. 2018, 7.

4. Saleh, Q.M.; Hensel, E.C.; Robinson, R.J. Method for Quantifying Variation in the Resistance of Electronic Cigarette Coils. International Journal of Environmental Research and Public Health 2020, 17, doi:10.3390/ijerph17217779.

5. Saleh, Q.; Hensel, E.C.; Robinson, R. Coil Resistance Testing Apparatus for VUSE ALTO; protocols.io, 2020 .

6. Robinson, R.J.; Eddingsaas, N.C.; DiFrancesco, A.G.; Jayasekera, S.; Hensel, E.C., Jr. A framework to investigate the impact of topography and product characteristics on electronic cigarette emissions. PLOS ONE 2018, 13, e0206341, doi:10.1371/journal.pone.0206341.

7. Hensel, E.C.; Eddingsaas, N.C.; DiFrancesco, A.G.; Jayasekera, S.; O'Dea, S.; Robinson, R.J. Framework to Estimate Total Particulate Mass and Nicotine Delivered to E-cig Users from Natural Environment Monitoring Data. Scientific Reports 2019.

8. Seber, G.A.F.; Wild, C.J. Nonlinear regression. hoboken. New Jersey: John Wiley E Sons 2003, 62, 63. 
9. MathWorks Inc, T. Matlab, 2021A; The MathWorks, Inc.: Natick, Apple Hill Campus, (Corporate Headquarters), 1 Apple Hill Drive, Natick, MA 01760-2098, 2021.

10. Lane, D.M. Online Statistics Education: A Multimedia Course of Study. Available online: http://onlinestatbook.com/ (accessed on Nov 7, 2021).

11. Huber, P.J. Robust Statistics; Wiley: 1981.

12. Dumouchel, W.; O'Brien, F. Integrating a robust option into a multiple regression computing environment. 1989; pp. 297-302.

13. Holland, P.W.; Welsch, R.E. Robust regression using iteratively reweighted least-squares. Communications in Statistics-theory and Methods 1977, 6, 813-827.

14. Street, J.O.; Carroll, R.J.; Ruppert, D. A note on computing robust regression estimates via iteratively reweighted least squares. The American Statistician 1988, 42, 152-154.

15. Lovell, M.C. A Simple Proof of the FWL Theorem. The Journal of Economic Education 2008, 39, 88-91.

16. Dawkins, L.; Cox, S.; Goniewicz, M.; McRobbie, H.; Kimber, C.; Doig, M.; Kośmider, L. 'Real-world' compensatory behaviour with low nicotine concentration e-liquid: subjective effects and nicotine, acrolein and formaldehyde exposure; 2018.

17. Dawkins, L.E.; Kimber, C.F.; Doig, M.; Feyerabend, C.; Corcoran, O. Self-titration by experienced e-cigarette users: blood nicotine delivery and subjective effects. Psychopharmacology 2016, 233, 2933-2941, doi:http://dx.doi.org/10.1007/s00213-016-4338-2.

18. Administration, F.a.D. 83 FR 11818 Tobacco Product Standard for Nicotine Level of Combusted Cigarettes. 2018, 83.

19. Primack, B.A.; Shensa, A.; Sidani, J.E.; Hoffman, B.L.; Soneji, S.; Sargent, J.D.; Hoffman, R.M.; Fine, M.J. Initiation of Traditional Cigarette Smoking after Electronic Cigarette Use Among Tobacco-Naïve US Young Adults. The American Journal of Medicine 2018, 131, 443.e441-443.e449, doi:https://doi.org/10.1016/j.amjmed.2017.11.005.

20. McKelvey, K.; Baiocchi, M.; Halpern-Felsher, B. Adolescents' and Young Adults' Use and Perceptions of Pod-Based Electronic Cigarettes. JAMA Network Open 2018, 1, e183535-e183535, doi:10.1001/jamanetworkopen.2018.3535.

21. Institute of, M. Ending the Tobacco Problem: A Blueprint for the Nation; The National Academies Press: Washington, DC, 2007. 